\begin{tabular}{ccc}
\hline International Journal of Medicine, $8(1)(2020) 18-18$ & International Journal of Medicine \\
SPC & Website: www.sciencepubco.com/index.php/IJM \\
Research paper & Medicine \\
\hline
\end{tabular}

\title{
COVID-19: what should we learn?
}

\author{
A Pozzi MD ${ }^{1}$, F Pozzi MD², A Campione MD², A Iorio MD ${ }^{1}$ \\ ${ }^{1}$ Cardiology department, Azienda Sanitaria Papa Giovanni XXIII, Bergamo-Italy \\ ${ }^{2}$ Neurosurgery department, Azienda Sanitaria Settelaghi, Varese-Italy \\ *Corresponding author E-mail: andreawellsvabg@gmail.com
}

\begin{abstract}
At the beginning of 2020 the COVID-19 outbreak had a massive impact on socio-economic, psychology and health system. The authors depict the possible weak points that influenced the spread infection. A collective decision making should be suggested in order to have an unvarying control to counteract future outbreaks, along with the needed of more health resources.
\end{abstract}

Keywords: COVD-19 outbreak, spread infection, health organization, health resources.

The COVID-19 has been declared an epidemic infection by the world Health Organization (WHO) on 30 January $2020^{1}$. Few days later the same WHO defined the outbreak more threatening than a terroristic attack. Indeed, the world quickly learnt the COVID-19 had a massive influence on socio-economics, psychology and healthcare systems. Initially, some physicians and politicians underestimated the real threat with a consequent spread of infection throughout different countries and, more deleteriously, an increased number of deaths. At the end of this epidemic a question should rise in our mind: what should we learn from the COVID-19 outbreak?

First of all, in case of outbreak social measures should be take to decrease the hazard of infection as much as possible. The lockdown (more or less restrictive) has been suggested in the majority of nations but in some regions it was not enough to counteract the COVID19 spread. As such, the number of patients raised within few days/weeks with a remarkable consequence on health system organization and resources. One of the main purposes of national health systems should be to provide the appropriate treatment (or the best available) for all the citizens, also during a pandemic or a terroristic attack. In Lumbardy, the most affected Italian region, the prevalence of patients admitted to intensive care units was $20 \%$ at the beginning of the outbreak, falling at $4 \%$ few weeks later ${ }^{2}$. The decreased number of patients needing an ICU admission was not related to a less severe disease presentation (or complications) or to a lower number of infected patients; instead, it was due to the lack of medical resources and ICU bed availability with a consequent raising number of deaths. This point should increase our concern about future outbreaks with an immediate need of a massive health resources. Although the COVID-19 has been considered (as it is) worse than a terroristic attack, it has its positive face. Indeed, the massive number of infected patients was spread across weeks, whereas the number of people involved in a massive terroristic attack (i.e 9/11) rise in few seconds. We believe this is the main issue scientific society along with politicians should deal with, both for the next outbreak or terroristic attack. Only with more resources and a better organization, we will be able to affirmatively answer to the second question: are we ready for another COVID-19?.

\section{References}

[1] World Health Organization 30 January 2020 conference

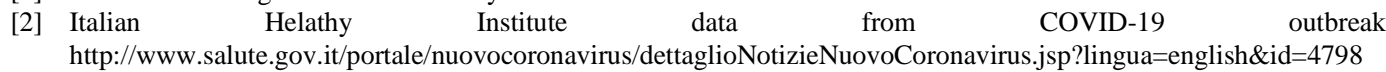

Italy: 